\title{
Self-Intimation, Infallibility, and Higher-Order Evidence
}

Eyal Tal

Abstract: The Self-Intimation thesis has it that whatever justificatory status a proposition has, i.e., whether or not we are justified in believing it, we are justified in believing that it has that status. The Infallibility thesis has it that whatever justificatory status we are justified in believing that a proposition has, the proposition in fact has that status. Jointly, Self-Intimation and Infallibility imply that the justificatory status of a proposition (bottom-level justification) closely aligns with the justification we have about that justificatory status (top-level justification). Self-Intimation has two noteworthy implications. First, assuming that we never have sufficient justification for a proposition and for its negation, we can derive Infallibility from Self-Intimation. Interestingly, there seems to be no equivalently simple way to derive Self-Intimation from Infallibility. This asymmetry provides reason for thinking that bottom-level justification rather than top-level justification drives the explanation for why the levels of justification align. Second, Self-Intimation suggests a counterintuitive treatment of information concerning what justificatory status a proposition has (higher-order evidence). It follows from Self-Intimation that we always have justification for the truth about whether a proposition is justified for us, and therefore, that higher-order evidence could change what we should believe on this matter only by misleading us. This permits forming beliefs about whether a proposition is justified for us without regard to higher-order evidence, and thus reveals a reason for thinking that top-level justification is evidentially inert.

Level-connection principles describe entailment relations between our justificatory status regarding a proposition $\mathrm{P}$ and our justificatory status regarding our justificatory status regarding $\mathrm{P}$. Two propositions represent our possible justificatory status regarding $\mathrm{P}$ :

JP/ᄀJP: $\quad$ S has $/$ lacks justification ${ }^{1}$ to believe P.

Four propositions represent our possible justificatory status regarding our justificatory status regarding $\mathrm{P}$ :

1 By 'justification' I mean sufficient, propositional, rational justification. If $S$ has justification to believe $P$, then whether or not $S$ justifiably believes $\mathrm{P}$, the proposition $\mathrm{P}$ enjoys sufficient support in S's situation. I use talk of justification, what we should believe, and what is rational to believe interchangeably. 
JJP / ᄀJJP: $\quad$ S has / lacks justification to believe that $\mathrm{S}$ has justification to believe $\mathrm{P}$.

$\mathrm{J} \neg \mathrm{JP} / \neg \mathrm{J} \neg \mathrm{JP}: \quad S$ has / lacks justification to believe that $S$ lacks justification to believe P.

Thus, level-connection principles relate certain pairs from the set consisting of six propositions: JP, $\neg \mathrm{JP}, \mathrm{JJ} P, \neg J \mathrm{JP}, \mathrm{J} \neg \mathrm{J} P$, and $\neg \mathrm{J} \neg \mathrm{J} P$.

Call JP and $\neg$ JP 'bottom-level' propositions, and JJP, $\neg \mathrm{JJP}, \mathrm{J} \neg \mathrm{JP}$, and $\neg \mathrm{J} \neg \mathrm{JP}$ 'top-level' propositions. $^{2}$ A bottom-up level-connection principle is a conditional whose antecedent is a bottom-level proposition, and whose consequent is a top-level proposition. A topdown level-connection principle is a conditional whose antecedent is a top-level proposition, and whose consequent is a bottom-level proposition. With two bottomlevel propositions and four top-level propositions, we can construct eight bottom-up and eight top-down level-connection principles. For convenience, we can represent all sixteen principles using eight biconditionals:
(1) JP $\leftrightarrow$ JJP
(2) JP $\leftrightarrow \neg J \mathrm{JP}$
(3) JP $\leftrightarrow \mathrm{J} \neg \mathrm{JP}$
(4) JP $\leftrightarrow \neg \neg \mathrm{JP}$
(5) $\neg \mathrm{JP} \leftrightarrow \mathrm{JJP}$
(6) $\neg \mathrm{JP} \leftrightarrow \neg \mathrm{J} \mathrm{P}$
(7) $\neg \mathrm{JP} \leftrightarrow \mathrm{J} \neg \mathrm{JP}$
(8) $\neg \mathrm{JP} \leftrightarrow \neg \mathrm{J} \neg \mathrm{JP}$

Some of the level-connection principles represented by these biconditionals are implausible. If (2) were true, for example, it would follow that whenever we should believe P we should not believe that we should believe P. But it is clear that in many cases we are justified both in believing $\mathrm{P}$ and in believing that we are so justified. It is also clear that in many cases we lack justification to believe that we should believe $\mathrm{P}$,

\footnotetext{
2 Others distinguish object-level from meta-level propositions and justification, or first/lower-order from second/higherorder. See Feldman (2005), Christensen (2010).
} 
and we in fact should not believe P. So (2) is wrong in both directions. Similar considerations let us rule out (3), (5) and (8). ${ }^{3}$ We are therefore left with eight levelconnection principles, which are represented by biconditionals (1), (4), (6), and (7). Of those eight, the four bottom-up principles and the four top-down principles can be paired as contrapositives:

\begin{tabular}{l|l}
\multicolumn{1}{c}{ Bottom-Up } & \multicolumn{1}{c}{ Top-Down } \\
\hline (BU1) JP $\rightarrow$ JJP & (TD1) $\neg J \mathrm{JP} \rightarrow \neg \mathrm{JP}$ \\
\hline (BU2) $\neg \mathrm{JP} \rightarrow$ J $\neg \mathrm{JP}$ & (TD2) $\neg \mathrm{J} \neg \mathrm{JP} \rightarrow \mathrm{JP}$ \\
\hline (BU3) JP $\rightarrow \neg$ J $\neg \mathrm{JP}$ & (TD3) J $\neg \mathrm{JP} \rightarrow \neg \mathrm{JP}$ \\
\hline (BU4) $\neg \mathrm{JP} \rightarrow \neg \mathrm{JJP}$ & (TD4) JJP $\rightarrow \mathrm{JP}$
\end{tabular}

Table 1. Enkratic level-connection principles

These remaining principles are quite strong. Combined, they yield a strict enkratic constraint, according to which rationality does not allow tension between what we should believe and what we should believe about what we should believe. ${ }^{4}$ Such a constraint is motivated by the thought that just as it is inconsistent to act akratically, i.e., in a way that the agent believes to be impermissible, it is similarly inconsistent to believe akratically, i.e., in a way that the agent believes to be irrational. If rationality prevents mismatch between what we should believe and what we should believe we should believe, no agent would be rationally permitted to have beliefs that are

3 We can use the propositions $\left(\mathrm{P}_{1}\right) 2+2=4$ and $\left(\mathrm{P}_{2}\right) 2+2=5$ as basis for counterexamples to all of (2), (3), (5) and (8), in all directions. I will not go through each counterexample, but here is how we could argue against (8). We should not believe $P_{2}$, so $\neg \mathrm{JP}_{2}$. Yet we should believe that we should not believe $\mathrm{P}_{2}$, so $\mathrm{J} \neg \mathrm{J}_{2}$. Likewise, we should not believe that we should not believe $\mathrm{P}_{1}$, so $\neg \mathrm{J} \neg \mathrm{JP}_{1}$. Yet we should believe $\mathrm{P}_{1}$, so $\mathrm{JP}_{1}$.

$4 \quad$ Horowitz (2014) refers to a similar (but weaker) constraint as the Non-Akrasia Constraint. Titelbaum (2015) calls his version the Akratic Principle. See Smithies (2012) and Greco (2014) for other varieties of this constraint. 
inconsistent in this sense. ${ }^{5}$ But, if any one of the remaining principles is false, it would mean that in some cases the levels of justification split, and rationality sometimes permits a kind of mismatch between our bottom-level and our top-level justificatory status. $^{6}$ Let us call these level-connection principles 'enkratic,' and a theory of justification committed to them an 'enkratic theory of justification.' This type of theory guarantees we are never required to adopt beliefs that we may not rationally endorse as rational beliefs, and therefore carries significant appeal. ${ }^{7}$

In what follows I do not take up the question of whether the enkratic levelconnection principles are correct. I focus instead on what these principles reveal about the relationship between bottom-level and top-level justification, if they are correct. We can begin by noting that some of the enkratic level-connection principles are derivable from others, assuming the impossibility of contradictory justification ${ }^{8}$ (ICJ). On this (modest) assumption, we never have justification to believe a proposition and justification to believe its negation. Equivalently:

(ICJ): $\quad \forall(\phi)(\neg \mathrm{J} \phi \vee \neg \mathrm{J} \neg \phi)$

5 Recall that the notion of justification in the level-connection principles is propositional. As such, they describe relations between propositions that we should believe and other propositions that we should believe. They do not describe relations between propositions that we in fact believe and propositions that we should believe. They entail, for instance, the wide-scope requirement not to believe $\mathrm{P}$ while believing that we should not believe P. They do not entail, for instance, the narrow-scope requirement to believe that we should believe $\mathrm{P}$, if we believe P. See Broome (1999) for a discussion of narrow-scope and wide-scope normative requirements.

6 Some level splits appear worse than others. For instance, if BU3 is false, then in some cases we should believe P but should also believe that we should not believe P. This seems worse than if BU1 is false, which would mean that in some cases we should believe P despite lacking justification that we should believe P. See Huemer (2011) and Smithies (2012) for reasons to think that the latter kind of case is also troublesome.

7 See Horowitz (2014) for reasons to avoid certain violations of the enkratic constraint.

8 I follow Dutant \& Littlejohn's (2016) terminology here. 
Given ICJ, the principles in row 1 of Table 1 entail those in row 3, and those in row 2 entail those in row 4 . However, a derivation in the opposite direction is not clearly available, as the principles in rows 3 and 4 do not seem to entail any of those in rows 1 and 2. ${ }^{9}$ Thus, the principles in rows 1 and 2 suffice for an enkratic theory of justification. Those rows include the principles of bottom-level self-intimation BU1 and BU2-the conjunction of which has been called the 'Self-Intimation thesis.' Rows 3 and 4 include the principles of top-level infallibility TD3 and TD4-the conjunction of which has been called the 'Infallibility thesis.' ${ }^{10}$

With Self-Intimation, that is, with JP $\rightarrow$ JJP and $\neg \mathrm{JP} \rightarrow \mathrm{J} \neg \mathrm{JP}$, we can derive Infallibility, that is, J $\neg \mathrm{JP} \rightarrow \neg$ JP and JJP $\rightarrow$ JP. First, JP $\rightarrow$ JJP entails J $\neg \mathrm{JP} \rightarrow \neg$ JP. For assume the antecedent of the latter, which is J $\neg$ JP. By ICJ, either $\neg$ JJP or $\neg$ J $\neg$ JP, and so $\neg$ JJP. Then, by $\mathrm{JP} \rightarrow \mathrm{JJP}$, it follows that $\neg \mathrm{JP}$, which is the consequent of J $\neg \mathrm{JP} \rightarrow \neg \mathrm{JP}$. Second, $\neg \mathrm{JP} \rightarrow \mathrm{J} \neg \mathrm{JP}$ entails JJP $\rightarrow$ JP. Assume the antecedent of the latter, which is JJP. By ICJ, either $\neg$ JJP or $\neg \mathrm{J} \neg \mathrm{J}$, and so $\neg$ J $\neg \mathrm{JP}$. Then, by $\neg \mathrm{JP} \rightarrow \mathrm{J} \neg \mathrm{J} \mathrm{P}$, it follows that JP, which is the consequent of JJP $\rightarrow$ JP. But no similarly simple derivation of Self-Intimation from Infallibility is available. ${ }^{11}$ So, given the plausible assumption of the impossibility of contradictory justification, we can derive Infallibility from Self-Intimation, but not the other way around.

\footnotetext{
9 Dutant \& Littlejohn (2016) note this as well.

10 I follow Smithies (2012) in using the names Self-Intimation and Infallibility for these principles.

11 When we assume Infallibility, that is, J $\neg \mathrm{JP} \rightarrow \neg \mathrm{JP}$ and JJP $\rightarrow \mathrm{JP}$, it is not clear how either JP $\rightarrow \mathrm{JJP}$ or $\neg \mathrm{JP} \rightarrow \mathrm{J} \neg \mathrm{JP}$ would follow. For example, let us assume the antecedent of the latter, that is, $\neg$ JP. From JJP $\rightarrow$ JP, it would follow that $\neg$ JJP. Since ICJ says that either $\neg$ JJP or $\neg$ J $\neg$ JP is true, ICJ is of no help here-we already have $\neg$ JJP, from which the disjunction $\neg$ JJP or $\neg$ J $\neg$ JP trivially follows. So the derivation comes to a halt, and no way to reach the desired J $\neg$ JP seems available. Of course, if JJP and J $\neg$ JP were the only justificatory statuses that we could have toward JP, then the derivation of Self-Intimation would succeed. But we cannot rule out the possibility that neither JJP nor $\mathrm{J} \neg \mathrm{JP}$ is true, i.e., that we should suspend judgment about whether JP.
} 
These entailment relations have not gone unnoticed. ${ }^{12}$ However, an important consequence of the asymmetry of derivation between Self-Intimation and Infallibility has been missed. The asymmetry sheds light on what feature of rationality could account for the matching between the levels of justification, which Self-Intimation and Infallibility together ensure. In other words, the asymmetry could help us understand in virtue of what the strict enkratic constraint obtains. It has been the subject of debate whether such a constraint should be explained by the bubbling up of justification, or by its trickling down. If justification bubbles up, our bottom-level justificatory status rationally constrains our top-level justificatory status. If justification trickles down, our top-level justificatory status rationally constrains our bottom-level justificatory status. ${ }^{13}$ So it seems as though these rival properties of justification could both explain why the levels of justification never split. But notice that if justification bubbles up, SelfIntimation follows, and if justification trickles down, Infallibility follows. Since we can derive Infallibility from Self-Intimation without substantial presuppositions, a bubbling up property of justification would explain why Self-Intimation and Infallibility are both true, and so why the levels of justification never split. Since we cannot derive SelfIntimation from Infallibility without substantial presuppositions, a trickling down property of justification would not be enough to explain why the levels of justification never split. A bubbling up property of justification accounts for the strict enkratic

12 Shoemaker (1996) discusses parallel entailments in the context of first-person access to sensory and intentional states. Dutant \& Littlejohn (2016) explicitly note such entailments in the context of rational justification.

13 Trickle-down proponents arguably include Christensen (2007), Elga (2007), and Feldman (2007). Bubble-up proponents arguably include Kelly (2005), Schoenfield (2015), Smithies (2012), Titelbaum (2015), and van Wietmarschen (2013). Here I leave out the option that both bottom-level justification and top-level justification affect each other until the levels align. This is an interesting option worth considering, although doing so here would distract from the focus of the project. Proponents of principles that give some weight to our bottom-level justification and some to our top-level justification may be on board with such a suggestion. See Kelly (2010), Sliwa \& Horowitz (2015), and Christensen (2016). 
constraint more simply than a trickling down one.

Self-Intimation implies the surprising perfect reliability of our top-level justification. Whichever justificatory status P has (JP or $\neg \mathrm{JP})$, we would have justification to believe it has that status. Importantly, we do not need to suppose that information about whether JP is true (higher-order evidence) affects whether we should believe $\mathrm{P}$, in order to explain the reliability of our top-level justification. ${ }^{14}$ A bubbling up property of bottom-level justification would do. But does Self-Intimation give us reason to think that higherorder evidence (HOE) cannot affect what we should believe? I believe it does. The basic idea is simple: whether or not we should believe P, Self-Intimation guarantees that we have sufficient justification to believe the truth about whether we should. So if we wonder whether JP is true, we need not look further than the justification that we already have in order to find out whether JP is true. ${ }^{15}$ Specifically, we need not look to what experts say about JP, nor to whether we tend to form rational beliefs about matters like $\mathrm{P}$, nor to any other source of information that seems relevant to whether we should believe $\mathrm{P} .{ }^{16}$ In fact, since any $\mathrm{HOE}$ is potentially misleading about JP, and since we already have sufficient justification to believe the truth about JP, using HOE in forming a belief about JP seems irrational.

A more detailed version of the argument starts with assuming Self-Intimation. From Self-Intimation it follows that for any proposition $\mathrm{P}$, we either have justification to

14 Kelly (2010) takes higher-order evidence to be "evidence about the normative upshot of the evidence to which [one] has been exposed." See Feldman (2009) and Christensen (2010) for similar conceptions.

15 Kiesewetter (2016) notes a parallel point.

16 Prudentially, we may need to use HOE given the difficulty of assessing our top-level justification without it. Going by our HOE may significantly boost our odds of forming the belief that corresponds to our evidence. But this kind of prudential necessity does not figure into rational requirements. Taking steps to improve our odds of forming beliefs that correspond to our evidence (like getting enough sleep, or rechecking our reasoning) is not rationally required. Prudential considerations like these may be behind the intuition that HOE is evidentially significant. For an opposing view, see Schechter (2013). 
believe $\mathrm{P}$ and to believe that we have justification to believe $\mathrm{P}$, or we lack justification to believe $\mathrm{P}$ and we have justification to believe that we lack justification to believe $\mathrm{P}$. We are thus in one of two possible kinds of situations: either JP $\wedge$ JJP (situation $S_{1}$ ) is the case, or $\neg \mathrm{JP} \wedge \mathrm{J} \neg \mathrm{JP}$ (situation $\mathrm{S}_{2}$ ) is.

Let higher-order evidence be information concerning whether we have justification to believe P in our situation Sn. ${ }^{17}$ Examples of HOE include expert testimony that our evidence supports $\mathrm{P}$, track record data about how good we are in forming rational doxastic attitudes, peer disagreement about whether $\mathrm{P}$, and so on. ${ }^{18}$ So defined, all incoming HOE either suggests that JP obtains in $\mathrm{Sn}_{\mathrm{n}}$ or that $\neg$ JP obtains in $\mathrm{S}_{\mathrm{n}}$. Let HOE+ stand for the former and HOE- stand for the latter.

Given these stipulations, four HOE / situation combinations exhaust logical space:

\begin{tabular}{l|c|c} 
& $H O E-(\neg \mathrm{JP}$ in Sn $)$ & $H O E+(\mathrm{JP}$ in Sn $)$ \\
\hline$S_{1}(\mathrm{JP} \wedge \mathrm{JJP})$ & A & B \\
\hline$S_{2}(\neg \mathrm{JP} \wedge$ J $\neg \mathrm{JP})$ & $\mathrm{C}$ & D
\end{tabular}

Table 2. Possible situation/higher-order evidence combinations

Now consider the proposition JP (S has justification to believe P). In scenario A our HOE suggests that $\neg J P$ in $S_{n}$. Since $S_{n}=S_{1}$ here, $\neg$ JP is false, and the HOE is misleading. In scenario B our HOE suggests that JP in $S_{n}$. Since $S_{n}=S_{1}$ here, we already have sufficient

17 Even if there are other kinds of HOE, the conclusion of the upcoming argument is significant as long as it is true of this kind of HOE.

18 We should distinguish HOE from evidence of evidence (EoE). EoE for P sometimes fails to be evidence for $\mathrm{P}$, and so if $\mathrm{HOE}$ were a kind of EoE, there would already be reason to wonder when it is genuine evidence. But the kind of evidence that is most relevant in this context is not evidence of evidence. For instance, if we know that our peers share our evidence, their disagreement would not be evidence that there is some evidence that we are not aware of. See Tal \& Comesaña (2017). 
justification to believe JP in the form of JJP. Thus the HOE in scenario B is superfluous support for the truth about JP. In scenario C our HOE suggests that $\neg J P$ in $S_{n}$. Since $S_{n}=$ S2 here, we already have justification to believe $\neg \mathrm{JP}$ in the form of J $\neg \mathrm{JP}$. Thus the HOE is again superfluous in this scenario. In scenario D our HOE suggests that JP in $S_{n}$. Since $S_{n}$ $=\mathrm{S}_{2}$ here, $\mathrm{JP}$ is false, and the HOE is again misleading. So, relative to JP, HOE is misleading in scenarios A and D, and superfluous in scenarios B and C.

HOE appears evidentially significant to JP in virtue of its explicit concern with whether JP is true in our situation Sn. ${ }^{19}$ But there is distance between the fact that HOE concerns a proposition that we care about, and the claim that it affects the rationally required attitude toward that proposition. If Self-Intimation is true, we always have sufficient justification for believing the truth about JP. Incoming HOE would either be misleading with respect to JP, or superfluous to our possessed justification for the truth about JP. This odd property of HOE should make us suspicious of views on which we must accord it significant evidential weight. If we know that some information is either misleading or superfluous in this way, it is hard to see what would be irrational with giving it no weight when forming our belief about JP. Given the HOE's potential to mislead us, and since we have sufficient and perfectly reliable justification about JP, it seems irrational to give the HOE any weight. So we rationally may, and arguably must, form our belief about JP without regard to HOE.

The discussion so far has proceeded in terms of which propositions an agent is justified in believing, rather than which of an agent's beliefs are justified (in widespread

19 The view that higher-order evidence affects what we should believe is a popular one. Most (e.g., Christensen (2007), Feldman (2007), Cohen (2013)) take it to require revision both of our belief about JP, and of our belief about P. Some (e.g., Worsnip (2018)) take it to be stronger evidence about JP than about P. The argument on offer here suggests that with Self-Intimation, incoming information about whether JP is true does not affect what we should believe about JP, let alone P. 
terminology, the discussion has proceeded in terms of propositional, rather than doxastic justification). Therefore, even if one grants that HOE is irrelevant to propositional justification, one could still maintain that it is relevant to doxastic justification. ${ }^{20}$ In that case, we may think that it is sometimes permitted to form beliefs about JP using our HOE. Moreover, I have been identifying what we have propositional justification to believe with what we should believe. But if what we have doxastic justification to believe matters to what we should believe, and if HOE could affect doxastic justification, HOE might affect what we should believe.

I will address these worries in reverse order. First, versions of Self-Intimation and Infallibility that concern what we should believe seem just as plausible as the versions I have been working with, which concern propositional justification. ${ }^{21}$ The arguments in this paper would run just the same when applied to those former versions. As long as Self-Intimation and Infallibility prevent mismatch between what we should believe and what we should believe we should believe, HOE will be misleading or superfluous relative to what we should believe about what we should believe. Second, then, supposing that HOE could provide a way for us to rationally believe the propositions that we should already believe would not detract from the claim that it does not change what we should believe. The trickling down story would remain dubious even if we grant that HOE can affect doxastic justification, and even if propositional justification and what we should believe come apart. So, while my arguments leave it open that HOE could sometimes matter to doxastic justification, HOE would still not make a difference to what we should believe.

\footnotetext{
20 Thanks to an anonymous Erkenntnis reviewer for this point.

21 Self-Intimation would be $(\mathrm{SP} \rightarrow \mathrm{SSP}) \wedge(\neg \mathrm{SP} \rightarrow \mathrm{S} \neg \mathrm{SP})$, and Infallibility would be $(\mathrm{S} \neg \mathrm{SP} \rightarrow \neg \mathrm{SP}) \wedge(\mathrm{SSP} \rightarrow$ SP).
} 
To conclude, a theory of justification that prohibits mismatch between the levels of justification is committed to the four level-connection principles that make up SelfIntimation and Infallibility. These principles could be explained by a view on which top-level justification is somehow fundamental, and swamps bottom-level justification so as to make it conform. But they are better explained by a view on which bottom-level justification is somehow fundamental, and ensures that top-level justification conforms. Self-Intimation entails Infallibility, secures an enkratic theory of justification, and suggests that higher-order evidence is evidentially inert. Since it represents a property of bottom-level justification, if true, Self-Intimation would give us reason to think that bottom-level justification is somehow fundamental.

\section{References}

Broome, John. (1999). “Normative Requirements”. Ratio 12: 398-419.

Christensen, D. (2007). “Epistemology and Disagreement: The Good News”. Philosophical Review 116: 187217.

—_ (2010). “Higher-Order Evidence”. Philosophy and Phenomenological Research 81 (1): 185-215.

—_ (2016). "Disagreement, Drugs, etc.: From Accuracy to Akrasia". Episteme 13(4): 397-422.

Cohen, S. (2013). "A Defense of the (almost) Equal Weight View". In Jennifer Lackey and David Christensen (Eds.), The Epistemology of Disagreement: New Essays. Oxford: Oxford University Press. 98120.

Dutant, F. \& Littlejohn, C. (2016). "Just do it? When to do what you judge you ought to do". Synthese DOI 10.1007/s11229-016-1220-z.

Elga, A. (2007). "Reflection and Disagreement”. Noûs 41 (3): 478-502.

Feldman, R. (2005) “Respecting the Evidence”. Philosophical Perspectives, volume 19: Epistemology (Blackwell, Oxford) pp. 95-119.

—_ (2007). "Reasonable Religious Disagreements". in L. Anthony (ed.) Philosophers without Gods: Meditations on Atheism and the Secular. Oxford University Press.

__ (2009). "Evidentialism, Higher-order Evidence, and Disagreement". Episteme 6: 294-312.

Greco, D. (2014). “A Puzzle About Epistemic Akrasia”. Philosophical Studies 167: 201-219.

Horowitz, S. (2014). “Epistemic Akrasia”. Noûs 48 (4): 718-744.

Huemer, M. (2011). “The Puzzle of Metacoherence”. Philosophy and Phenomenological Research 82 (1): 1-21. Kelly, T. (2005). "The Epistemic Significance of Disagreement". Oxford Studies in Epistemology 1: 167-196. 
_- (2010). “Peer Disagreement and Higher-Order Evidence”. In T. Warfield and R. Feldman (Ed.), Disagreement. Oxford University Press. 111-175.

Kiesewetter, B. (2016). "You ought to $\varphi$ only if you may believe that you ought to $\varphi$ ". The Philosophical Quarterly 66 (265): 760-782.

Schechter, J. (2013). "Rational Self-Doubt and the Failure of Closure". Philosophical Studies 163: 428-452.

Schoenfield, M. (2015). “A Dilemma for Calibrationism". Philosophy and Phenomenological Research 91(2): 425-455.

Shoemaker, S. (1996). The First-Person Perspective and Other Essays. Cambridge University Press.

Sliwa, P. \& Horowitz, S. (2015). “Respecting All the Evidence”. Philosophical Studies 172 (11): 2835-2858.

Smithies, D. (2012). "Moore's Paradox and the Accessibility of Justification". Philosophy and Phenomenological Research 85 (2): 273-300.

Tal, E. \& Comesaña, J. (2017). “Is Evidence of Evidence Evidence?”. Nô̂s 51 (1): 95-112.

Titelbaum, M. (2015). “Rationality's Fixed Point (Or: In Defense of Right Reason)." In J. Hawthorne (ed.) Oxford Studies in Epistemology 5. Oxford University Press. 253-294.

van Wietmarschen, H. (2013). "Peer Disagreement, Evidence, and Well Groundedness". Philosophical Review 122 (3): 395-425.

Worsnip, A. (2018). "The Conflict of Evidence and Coherence". Philosophy and Phenomenological Research 96 (1): 3-44. 